\title{
Образование акцепторных центров в CdHgTe под воздействием воды и термообработок
}

\author{
(С) Г.Ю. Сидоров, Ю.Г. Сидоров, В.А. Швец, В.С. Варавин
}

Институт фризики полупроводников им. А. В. Ржанова Сибирского отделения Российской академии наук, 630090 Новосибирск, Россия

E-mail: sidorov@isp.nsc.ru

Поступила в Редакцию 25 ноября 2020 г.

В окончательной редакции 7 декабря 2020 г.

Принята к публикации 16 декабря 2020 г.

Исследовано влияние деионизованной воды и прогрева образцов эпитаксиальных пленок CdxHg1-хТе на их холловские и эллипсометрические параметры. Обработка водой уменьшает показатель преломления естественного окисла $\mathrm{Cd}_{x} \mathrm{Hg}_{1-x}$ Te с 2.1 до 1.2-1.4. Это означает, что происходит введение в окисел вещества с малым показателем преломления, таким как вода. Кипячение в воде приводит к образованию в $\mathrm{Cd}_{x} \mathrm{Hg}_{1-x}$ Tе акцепторов с концентрациями до $10^{19} \mathrm{~cm}^{-3}$. Изменение кислотности среды от щелочной до кислой замедляет скорость образования акцепторов. Прогрев после выдержки в воде также приводит к образованию акцепторов. Сделано заключение, что вода, в том числе присутствующая в слое естественного окисла, приводит к образованию акцепторов в $\mathrm{Cd}_{x} \mathrm{Hg}_{1-x} \mathrm{Te}$. Концентрация акцепторов растет с температурой обработки и количеством доступной воды.

Ключевые слова: CdHgTe, естественный окисел, акцепторы, термообработка.

DOI: $10.21883 /$ FTP.2021.04.50734.9560

\section{1. Введение}

Опыт работы с фотоприемниками на основе $\mathrm{Cd}_{x} \mathrm{Hg}_{1-x}$ Te кадмий-ртуть-теллур (КРТ) показывает, что в ряде случаев со временем хранения происходит изменение их параметров. Например, в работе [1] наблюдалась деградация фоторезисторов из КРТ $n$-типа проводимости. Это было вызвано непреднамеренным введением акцепторных центров и компенсацией носителей заряда в материале, что привело к снижению проводимости, а также к снижению времени жизни неосновных носителей. Образование неконтролируемых акцепторов наблюдалось при прогреве нелегированных слоев [2]. Акцепторами в КРТ могут являться либо примеси, либо вакансии в подрешетке металла. В условиях соблюдения строжайшей чистоты материалов введение примесей в наблюдаемых концентрациях мало вероятно. В работе [1] деградация происходила при комнатной температуре, при которой равновесная концентрация вакансий $<10^{13} \mathrm{~cm}^{-3}$, так что образование вакансий не могло вызвать наблюдаемый эффект. В работе [2] отжиг завершался длительным прогревом в насыщенных парах ртути, так что образование вакансий также не могло произойти.

В работе [3] было показано, что кипячение легированных индием пленок КРТ $n$-типа проводимости в деионизованной воде приводит к введению акцепторов, концентрация которых может превышать величину $10^{17}, \mathrm{~cm}^{-3}$. Осталось неясным, необходим ли индий для введения акцепторов. В работе [4] было прослежено изменение эффективной концентрации от времени кипячения. Эффективная концентрация носителей определялась как величина, обратная измеренному значению коэффици- ента Холла, и при больших значениях соответствует концентрации в рабочем слое КРТ [5]. При временах кипячения несколько десятков минут произошел переход от исходной электронной проводимости к дырочной. При временах кипячения $\sim 10^{3}$ мин эффективная концентрация дырок превысила величину $10^{18} \mathrm{~cm}^{-3}$. Согласно результатам послойных измерений образцов [6], подвергнутых кипячению, у поверхности концентрация дырок с увеличением времени кипячения растет и достигает значений $10^{19} \mathrm{~cm}^{-3}$, а при увеличении глубины концентрация резко уменьшается, что соответствует диффузионному процессу. На глубине > 2 мкм концентрация уменьшается медленно, что указывает на наличие путей ускоренной диффузии. При отжиге прошедших кипячение образцов при $210^{\circ} \mathrm{C}$ в насыщенных парах ртути аннигиляции акцепторов не происходит. Следовательно, образующиеся при кипячении акцепторные центры не являются вакансиями в подрешетке металла. Эти результаты однозначно показывают, что вода при кипячении КРТ может служить причиной образования акцепторных центров. Возникает вопрос - не могла ли вода служить причиной образования неконтролируемых акцепторов, наблюдавшихся в работах $[1,2]$, хотя прямого контакта КРТ с фазой жидкой воды в этих работах при образовании акцепторов не было. В связи с тем что жидкостные обработки КРТ с использованием водных растворов используются регулярно, представляется необходимым исследование влияния этих обработок на возможность изменения свойств КРТ.

Цель данного исследования - выяснить, является ли присутствие воды, в том числе и не в виде жидкой фазы, достаточным условием для неконтролируемого введения акцепторов в пленки КРТ. 
Таблица 1. Концентрация и подвижность носителей заряда в образцах КРТ МЛЭ после кипячения в различных средах

\begin{tabular}{l|c|c}
\hline \multicolumn{1}{c|}{ Тип обработки } & $\begin{array}{c}\text { Концентрация } \\
\text { носителей, } \mathrm{cm}^{-3}\end{array}$ & $\begin{array}{c}\text { Подвижность носителей, } \\
\mathrm{cm}^{2} \cdot \mathrm{B}^{-1} \cdot \mathrm{c}^{-1}\end{array}$ \\
\hline Необработанный образец & $n=4.0 \cdot 10^{14}$ & 80000 \\
Кипячение в деионизованной воде $45 \mathrm{mин}$ & $p=1.2 \cdot 10^{16}$ & 330 \\
Кипячение в деионизованной воде $+\mathrm{NH}_{4} \mathrm{OH}(25 \%) 10$ мл/л 45 мин & $p=1.4 \cdot 10^{16}$ & 340 \\
Кипячение в деионизованной воде $+\mathrm{HCl}(35 \%) 10$ мл/л 45 мин & $n=1.2 \cdot 10^{14}$ & 11000 \\
Кипячение в деионизованной воде $+\mathrm{HCl}(35 \%) 50$ мл/л 90 мин & $n=2.5 \cdot 10^{14}$ & 72000
\end{tabular}

\section{2. Экспериментальные результаты и их обсуждение}

Проведены холловские измерения концентрации и подвижности носителей заряда в образцах КРТ до и после обработок как кипячением в водных растворах с различным $\mathrm{pH}$, так и при выдержке образцов в водных растворах при комнатной температуре с последующим прогревом при $115^{\circ} \mathrm{C}$. Были проведены измерения параметров окисных слоев на КРТ спектральным эллипсометром Woollam M-2000X. Обработка результатов измерений проводилась программой Complete EASE, в которой для определения толщины окисла и его показателя преломления использовалась модель структуры, состоящей из двух сред: подложки КРТ и слоя окисла КРТ. Показатель преломления слоя в зависимости от длины волны описывался дисперсионной моделью Коши: $n=n_{0}+A / \lambda^{2}+B / \lambda^{4}$. Подгоночными параметрами при обработке результатов служили: состав КРТ вблизи поверхности, толщина слоя окисла и коэффициенты $n_{0}$, $A$ и $B$ в модели Коши.

Использовались гетероэпитаксиальные структуры $\mathrm{Hg}_{1-x} \mathrm{Cd}_{x} \mathrm{Te} / \mathrm{CdTe} / \mathrm{ZnTe} / \mathrm{Si}(013)$ и $\mathrm{Hg}_{1-x} \mathrm{Cd}_{x} \mathrm{Te} / \mathrm{CdTe} /$ $\mathrm{ZnTe} / \mathrm{GaAs}(013)$ с варизонными слоями, выращенные методом молекулярно-лучевой эпитаксии (МЛЭ) [7]. Содержание CdTe в слоях КРТ составляло $x=0.22$ и $x=0.30$; а у поверхности верхнего варизонного слоя доходило до 0.43 (рис. 1).

Кипячение проводилось в кварцевой посуде в чистой деионизованной воде и с добавлением в воду аммиака или соляной кислоты. Влияние кипячения в разных средах на холловские параметры приведено в табл. 1.

Как видно из таблицы, переход проводимости из исходного $n$-типа в $p$-тип при кипячении в чистой воде или в воде с добавлением аммиака (щелочная среда) происходит за время $<45$ мин. При добавлении соляной кислоты (кислая среда) образование акцепторов замедляется, а скорость образования акцепторов уменьшается с ростом концентрации кислоты. Об этом свидетельствует величина эффективной подвижности после обработки.

При технологических обработках КРТ в процессе изготовления ИК-фотоприемников прогрев в водных средах обычно не используется, однако непреднамеренные акцепторы в ряде случаев образуются. Здесь необходимо учитывать, что на поверхности КРТ при экспозиции на

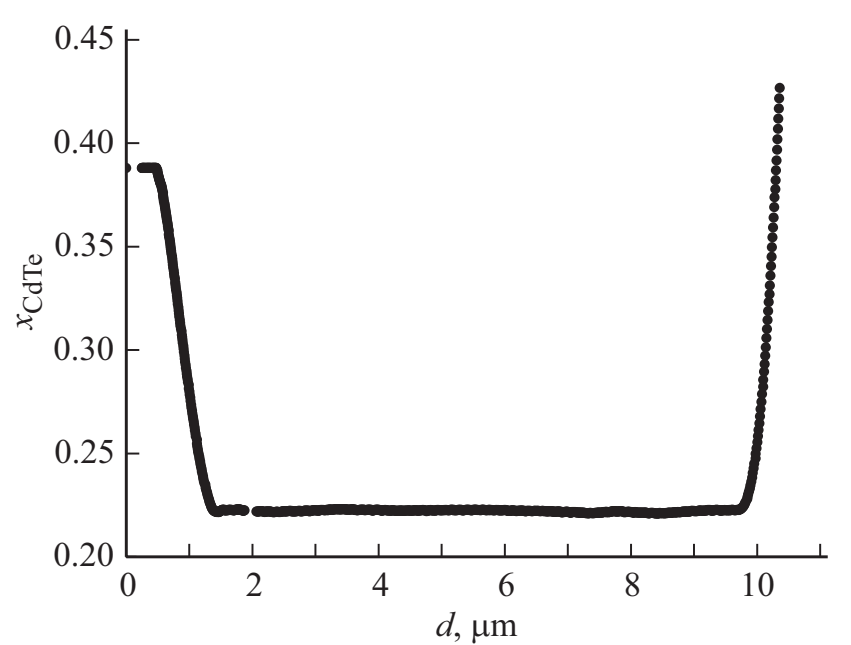

Рис. 1. Профиль состава по толщине пленки КРТ с варизонными слоями на границе с буферным слоем CdTe и на поверхности, измеренный в процессе выращивания встроенным одноволновым эллипсометром. Толщина отсчитывается от границы с буферным слоем CdTe в рабочем однородном слое $x=0.223$.

воздухе образуется слой естественных окислов теллура, кадмия и ртути, который может содержать воду. Согласно эллипсометрическим измерениям, после недельной экспозиции КРТ на воздухе слой естественного окисла достигает величины $\sim 2$ нм с показателем преломления $n \geq 2$. При прогревах пленок КРТ как в атмосфере инертного газа, так и на воздухе происходит уменьшение толщины окисла и увеличение показателя преломления, как показано на рис. 2 для образца, прогретого на воздухе при $170^{\circ} \mathrm{C}$.

Толщина окисла за время прогрева уменьшилась с 2.6 до $1.9 \mathrm{Hм}$, а показатель преломления увеличился с 2.0 до 2.1, что свидетельствует об увеличении плотности окисла. Уменьшение толщины и увеличение показателя преломления связано с высыханием окисла (удалением воды). Отсюда следует, что даже без обработок в водных растворах в окисном слое КРТ, экспонировавшемся на воздухе, присутствует некоторое количество воды, возможно, в виде кристаллогидратов окислов кадмия и ртути.

Эллипсометрические измерения показывают, что окисный слой претерпевает значительные изменения, 
Таблица 2. Параметры окисного слоя КРТ МЛЭ после обработки в различных средах

\begin{tabular}{|c|c|c|c|c|c|c|}
\hline $\begin{array}{c}\text { № } \\
\text { образца }\end{array}$ & Процедура & Среда & $\begin{array}{c}\text { Продолжи- } \\
\text { тельность }\end{array}$ & $\begin{array}{l}\text { Толщина } \\
\text { окисного } \\
\text { слоя, нм }\end{array}$ & $\begin{array}{c}\text { Состав на } \\
\text { поверх- } \\
\text { ности, } x\end{array}$ & $N$ \\
\hline 1 & Исходный образец после роста & & & 1.84 & 0.41 & 2.11 \\
\hline 2 & Кипячение & Деионизованная вода & 30 мин & 2.30 & 0.38 & 1.31 \\
\hline 3 & Кипячение & $\begin{array}{l}\text { Деионизованная вода } \\
+\mathrm{HCl}(35 \%) 1 \text { мл/литр }\end{array}$ & 60 мин & 2.89 & 0.34 & 1.40 \\
\hline 4 & Выдержка при комнатной температуре & Деионизованная вода & 15 мин & 1.76 & 0.41 & 1.35 \\
\hline 5 & Выдержка при комнатной температуре & $\begin{array}{l}\text { Буферный травитель } \\
\mathrm{NH}_{4} \mathrm{~F}(40 \%): \operatorname{HF}(46 \%)=(7: 1)\end{array}$ & 15 мин & 1.53 & 0.41 & 1.23 \\
\hline 6 & Выдержка при комнатной температуре & $\begin{array}{l}\text { Деионизованная вода } \\
+ \text { аммиак }(25 \%) \quad 10 \text { мл/литр }\end{array}$ & 15 мин & 1.02 & 0.41 & 1.22 \\
\hline \multirow{2}{*}{7} & \multirow{2}{*}{ Выдержка при комнатной температуре } & $\begin{array}{l}\text { Деионизованная вода } \\
+ \text { аммиак(25\%) } 10 \text { мл/литр }\end{array}$ & 15 мин & \multirow{2}{*}{0.28} & \multirow{2}{*}{0.41} & \multirow{2}{*}{1.19} \\
\hline & & $\begin{array}{l}\text { Буферный травитель } \\
\mathrm{NH}_{4} \mathrm{~F}(40 \%): \mathrm{HF}(46 \%)=(7: 1)\end{array}$ & 50 мин & & & \\
\hline
\end{tabular}

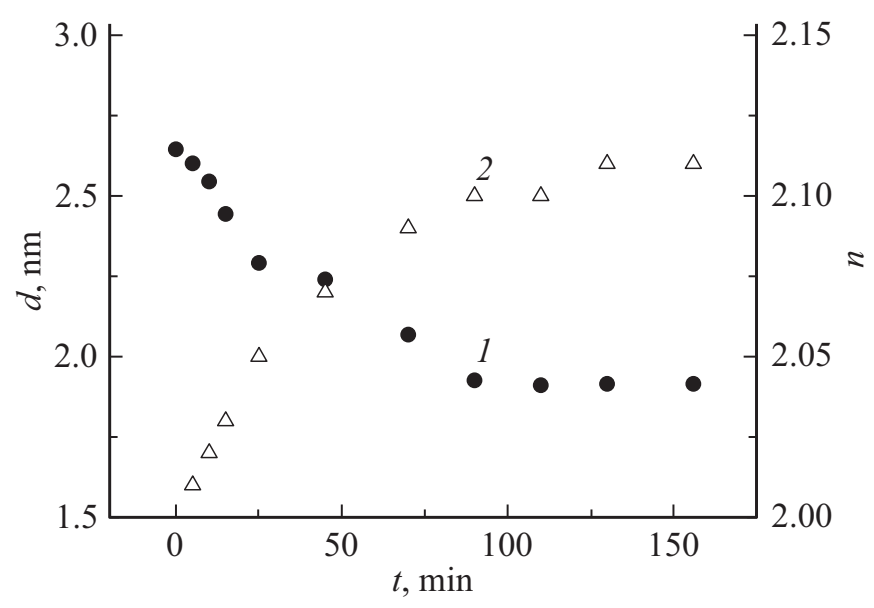

Рис. 2. Изменение толщины $d(1)$ и показателя преломления $n(2)$ окисного слоя КРТ в зависимости от времени прогрева $t$ на воздухе при температуре $170^{\circ} \mathrm{C}$.

как при кипячении, так и при обработке водными растворами при комнатной температуре, причем при кипячении происходит растворение КРТ. Использование структур с варизонным слоем (рис. 1) позволяло измерять количество растворившегося при обработке КРТ по изменению состава на поверхности.

Толщина окисного слоя при кипячении, как в нейтральной среде, так и в кислотной, увеличивается, а показатель преломления n и содержание CdTe в поверхностном слое КРТ уменьшается, как это видно из табл. 2, где приведены результаты для образцов, вырезанных из одной пластины. При комнатной температуре обработки водными растворами уменьшают толщину и показатель преломления слоя окислов.
Изменение состава КРТ на поверхности при кипячении (образцы 2 и 3) указывает на травление КРТ. Из рис. 1 по изменению состава на поверхности была определена толщина стравленного слоя варизонки. В образце 2 она составила 30 нм, в образце $3-90$ нм. При этом была введена поправка на разницу в результатах измерения поверхностного состава встроенным одноволновым эллипсометром $(x=0.43)$ и спектральным эллипсометром $(x=0.41)$. Вследствие травления в кислом растворе поверхность обедняется элементами второй группы и удаляется слой, в котором образовались акцепторы. Возможно, с этим связана необходимость увеличения времени кипячения в кислом растворе для того, чтобы произошла конверсия типа проводимости.

Как следует из табл. 2, при обработке водой при комнатной температуре (образец 4) толщина окисного слоя немного уменьшилась, что свидетельствует о частичном растворении окислов. Резко упал показатель преломления - с 2.11 до 1.35, т. е. сильно уменьшилась оптическая плотность окисла, что соответствует введению в окисел большого количества вещества с малым показателем преломления, каким является вода. Еще большее растворение окисла происходит в щелочном и кислотном растворах (образцы 5 и 6). Последовательная обработка в щелочном, а затем в кислом растворе удаляет пленку окисла практически полностью (образец 7). Получается, что при кислотной и щелочной обработках растворяются разные компоненты окисной пленки - вероятно, в щелочном растворе преимущественно растворяется окисел теллура, а в кислотном - окислы кадмия и ртути. Основным результатом проведенных измерений является то, что обработки КРТ водными растворами уменьшают показатель преломления окисного слоя, что свидетельствует о насыщении окисного слоя водой. 
Таблица 3. Параметры пленки КРТ МЛЭ после обработки водой и прогрева

\begin{tabular}{l|c|c|c}
\hline \multicolumn{1}{c|}{ Тип обработки } & $\begin{array}{c}\text { Концентрация } \\
\text { носителей, } \mathrm{cm}^{-3}\end{array}$ & $\begin{array}{c}\text { Подвижность } \\
\text { носителей, } \mathrm{cm}^{2} \cdot \mathrm{B}^{-1} \cdot \mathrm{c}^{-1}\end{array}$ & $\begin{array}{c}\text { Проводимость, } \\
\text { Ом }^{-1} \cdot \mathrm{cm}^{-1}\end{array}$ \\
\hline Исходные параметры & $2.60 \cdot 10^{14}$ & 99000 & 4.59 \\
Необработанный образец + прогрев & $2.45 \cdot 10^{14}$ & 93400 & 4.04 \\
Выдержка в деионизованной воде 5 мин + прогрев & $1.88 \cdot 10^{14}$ & 6640 & 0.22
\end{tabular}

В образце, выдержанном в воде при комнатной температуре, при последующих прогревах даже при относительно невысоких температурах образуются акцепторы. В табл. 3 приведены результаты прогрева необработанного и обработанного водой образцов. Прогрев проводился при $115^{\circ} \mathrm{C}$ в течение 90 ч в атмосфере инертного газа.

Как видно из таблицы, нелегированные образцы nтипа с необработанной в водных средах поверхностью выдерживают прогрев практически без изменений (с уменьшением проводимости на уровне $10 \%$, что не превышает ошибки измерения). Обработка водными растворами перед прогревом однозначно вводит акцепторы - проводимость $n$-типа падает более чем на порядок. А отжиг обработанных водой образцов при $210^{\circ} \mathrm{C}$ в ряде случаев приводит к конверсии в $p$-тип даже при насыщенном давлении паров ртути. Это свидетельствует о том, что образующиеся акцепторы не являются вакансиями ртути.

При изготовлении ИК-фотоприемников из КРТ используются чередующиеся обработки в водных растворах и термические обработки - проявляется и сушится фоторезист при фотолитографии, сушатся образцы после жидкостных обработок, прогревы используются для модификации свойств КРТ. В результате таких последовательностей обработок фотоэлектрические параметры КРТ могут изменяться неконтролируемым образом.

Что касается природы акцепторов, образуемых водой в КРТ, в работе [6] было сделано предположение, что образование акцепторов связано с внедрением в КРТ водорода в результате диссоциации молекул воды. Это предположение подтверждалось экспериментом, в котором образец КРТ $n$-типа, обработанный водным раствором серной кислоты с приложением отрицательного напряжения (образец КРТ в положении катода), с увеличением времени обработки изменил тип проводимости на дырочный. Прямое доказательство растворения водорода в КРТ и вызванное этим изменение электрофизических свойств было продемонстрировано в работе [3] - кипячение образцов КРТ в тяжелой воде приводило к изменению типа проводимости с электронного на дырочный с концентрацией дырок $2.5 \cdot 10^{17} \mathrm{~cm}^{-3}$. При этом вторично-ионная масс-спектрометрия (ВИМС) обнаруживала содержание дейтерия в образцах на уровне $10^{17} \mathrm{~cm}^{-3}$. В работе [8] проведены расчеты образования дефектов, создаваемых водородом в теллуриде кадмия. Согласно данным этой работы, водород образует в CdTe доноры, когда встает в связь $\mathrm{Cd}-\mathrm{Te}$, и образует акцепторы, когда встает в междоузлие, окруженное атомами кадмия. При исследовании прямой гидрогенизации в водороде при облучении ультрафиолетом [9] обнаружено, что содержание ртути на поверхности уменьшается примерно на 20\% с видимым образованием комплексов $\mathrm{Hg}-\mathrm{H}$, $\mathrm{Cd}-\mathrm{H}$. Однако при этом у поверхности образуется вырожденный слой $n$-типа проводимости. Акцепторные центры, образуемые в КРТ водой, видимо, помимо атома водорода включают и другие компоненты, например дефекты структуры КРТ.

\section{3. Заключение}

Проведенное исследование позволяет утверждать, что вода, в том числе и абсорбированная в слое естественного окисла, служит источником образования акцепторных центров в КРТ. Количество образовавшихся акцепторных центров растет с температурой, продолжительностью воздействия и количеством доступной воды и может достигать $10^{19} \mathrm{~cm}^{-3}$. Отжиг в насыщенных парах ртути не приводит к аннигиляции образовавшихся акцепторов. Выяснение природы акцепторов требует дальнейших исследований.

\section{Конфликт интересов}

Авторы заявляют, что у них нет конфликта интересов.

\section{Список литературы}

[1] А.В. Филатов, Е.В. Сусов, А.В. Гусаров, Н.М. Акимова, В.В. Крапухин., В.В. Карпов, В.И. Шаевич. Оптич. журн., 76 (12), 49 (2009).

[2] W.M.C. Hughes, M.L. Swanson, J.C. Austin. J. Electron. Mater., 22 (8), 1011 (1993).

[3] P. Boieriu, C.H. Grein, J. Garland, S. Velicu, C. Fulk, A. Stoltz, L. Bubulac, J.H. Dinan, S. Sivananthan. J. Electron. Mater., 35 (6), 1885 (2006).

[4] G.Yu. Sidorov, Yu.G. Sidorov, V.S. Varavin. Phys. Status Solidi C, 7 (6), 1630 (2010).

[5] П.А. Бахтин, С.А. Дворецкий, С. Варавин, А.П. Коробкин, Н.Н. Михайлов, Ю.Г. Сидоров. ФТП, 38 (10), 1203 (2004).

[6] В.С. Варавин, Г.Ю. Сидоров, М.О. Гарифуллин, А.В. Вишняков, Ю.Г. Сидоров. ФТП, 45 (3), 408 (2011). 
[7] М.В. Якушев, Д.В. Брунев, В.С. Варавин, В.В. Васильев, С.А. Дворецкий, И.В. Марчишин, А.В. Предеин, И.В. Сабинина, Ю.Г. Сидоров, А.В. Сорочкин. ФТП, 45 (3), 396 (2011).

[8] Zs. Rak, S.D. Mahanti, Krishna C. Mandal. J. Electron. Mater., $38(8), 1539$.

[9] G.D. Davis, N.E. Byer, R.A. Riedel, R.R. Daniels, G. Margaritondo. J. Vac. Sci. Technol. A, 3 (1), 203 (1985).

Редактор Г.А. Оганесян

\section{Formation acceptor centers in $\mathrm{CdHgTe}$ as a result of water and heat treatments}

G.Yu. Sidorov, Yu.G. Sidorov, V.A. Shwets, V.S. Varavin

Rzhanov Institute of Semiconductor Physics,

Siberian Branch of Russian Academy of Sciences,

630090 Novosibirsk, Russia

Abstract Influence storage and boiling in deionized water and heat treatments of epitaxial films $\mathrm{Cd}_{x} \mathrm{Hg}_{1-x} \mathrm{Te}$ on the Hall and ellipsometric parametres is investigated. Water treatment reduces refractive index of native $\mathrm{Cd}_{x} \mathrm{Hg}_{1-x}$ Te oxide from 2.1 to $1.2-1.4$. It means that matter with a lower refractive index, such as water, is introduced in the oxide. Boiling in water leads to formation of acceptors in $\mathrm{Cd}_{x} \mathrm{Hg}_{1-x} \mathrm{Te}$ with concentrations up to $10^{19} \mathrm{~cm}^{-3}$. Change of medium's $\mathrm{pH}$ from alkaline to the acidic decreases the speed of acceptors formation. Heat treatments after storage in water also leads to formation of acceptors. The conclusion is made, that water medium or water absorbed by native oxide layer leads to formation of acceptors in $\mathrm{Cd}_{x} \mathrm{Hg}_{1-x} \mathrm{Te}$. Concentration of acceptors grows with temperature of treatments and quantity of accessible water. 